\title{
Impactos do gerencialismo no desenvolvimento da Educação Profissional Tecnológica no Brasil
}

\author{
Impacts of new managerialism on the development of Technological \\ Professional Education in Brazil
}

\author{
Recebido: 26/07/2020 | Revisado: \\ 19/11/2020 | Aceito: 12/03/2021 | \\ Publicado: 16/06/2021 \\ Celia Cristina Pereira da Silva Veiga \\ ORCID: https://orcid.org/0000-0003-4932- \\ 5968 \\ Universidade Federal Rural do Rio de \\ Janeiro \\ E-mail: celiacveiga@gmail.com \\ José dos Santos Souza \\ ORCID: https://orcid.org/0000-0001-5433- \\ 0812 \\ Universidade Federal Rural do Rio de \\ Janeiro (UFRRJ) \\ E-mail: jsantos.ufrri@gmail.com
}

Como citar: VEIGA, C. C. P. S.; SOUZA, S. J. Impactos do gerencialismo no desenvolvimento da Educação Profissional Tecnológica no Brasil. Revista Brasileira da Educação Profissional e Tecnológica, [S.I.], v. 1, n. 20, p. 1-15 e10834, Jun. 2021. ISSN 2447-1801.

This work is licensed under a Creative Commons Attribution 4.0 Unported License.

\section{Resumo}

O Curso Superior de Tecnologia (CST) foi regulado no contexto de normatização de um conjunto de políticas que visam à hegemonia em torno do projeto de vida e sociedade necessário à manutenção do sistema econômico vigente. Nossa questão de estudo é a relação entre a regulação e o desenvolvimento dos CSTs e a expansão da ideologia gerencial. $O$ objetivo é analisar as relações entre 0 gerencialismo e o desenvolvimento do CST. Trata-se de pesquisa básica, com abordagem qualitativa e finalidade explicativa, a partir de fontes bibliográficas. Os resultados evidenciam a organização de um modelo de formação em nível superior que explicita a sofisticação da divisão social do conhecimento, na qual, o CST funciona como instrumento de conformação em torno da concepção de vida e sociedade gerencialista.

Palavras-chave: Neoliberalismo. Gerencialismo. Divisão social do conhecimento. Educação profissional tecnológica. Curso superior de tecnologia.

\begin{abstract}
The Higher Technology Course (CST) was regulated in the context of standardizing a set of policies that aim at the hegemony around the life and society project necessary to maintain the current economic system. Our study question is the relationship between the regulation and development of CSTs and the expansion of new managerial ideology. The objective is to analyze the relationship between new managerialism and the development of CST. It is basic research, with a qualitative approach and explanatory purpose, from bibliographic sources. The results show the organization of a training model at a higher level that explains the sophistication of the social division of knowledge, in which the CST works as an instrument of shaping around the conception of life and managerial society.
\end{abstract}

Keywords: Neoliberalism. New managerialism. Social division of knowledge. Technological Professional Education. Higher Technology Course. 


\section{INTRODUÇÃO}

O fundamento sócio-histórico sobre o qual desenvolvemos este artigo parte da crise orgânica do capital evidenciada entre o final da década de 1960 e início de 1970 (HOBSBAWN, 1977; HARVEY, 2007; DARDOT; LAVAL, 2016; DUMÉNIL; LÉVY, 2013; SOUZA, 2016, 2018), que se expressa em contradições insanáveis entre estrutura e superestrutura impondo o desenvolvimento de ofensivas pelo bloco no poder ${ }^{1}$ para retomada da direção da sociedade (GRAMSCI, 2016, p. 37). Souza (2016, 2018) denominou recomposição burguesa ao conjunto de ofensivas voltadas à manutenção do capitalismo evidenciadas nesse contexto. Tais ofensivas foram situadas principalmente no regime de acumulação rígida e no cerce da administração estatal pelo discurso de aumento da dívida pública impulsionada pela política do Welfare State $^{2}$. A partir disso, a reestruturação da produção se materializou pela adoção do regime de acumulação flexível e as relações entre sociedade civil e sociedade política foram reformuladas por meio de ampla reforma do Estado ${ }^{3}$.

Nesse contexto, as políticas educacionais foram reformadas, de modo que se adequassem ao novo modelo de produção e reprodução da vida material impulsionado pela recomposição burguesa. Para isso, a participação dos organismos internacionais foi incisiva na organização e promoção de mudanças que foram explicitadas tanto na política de educação formal, quanto na própria concepção de educação e de seu papel preponderante na formação do humano de novo tipo.

A educação como um direito de todos está presente nas formulações das políticas globais que massificaram seu valor, a tal ponto que a educação formal se tornou demanda da classe trabalhadora. Não obstante, o processo de desenvolvimento do capitalismo depende da racionalização da vida, que está intimamente vinculada ao desenvolvimento educacional da sociedade. A promoção da educação formal presente no discurso dominante vincula certificação e emprego, educação e prosperidade, como fórmula de "sucesso" na vida pela ascensão social, ampliando o fetiche pelo diploma. Tal processo sofistica e aprofunda a mercantilização da educação e do próprio humano subsumido pela ideia de capital.

Nesse contexto, as possibilidades de certificação são ampliadas, seguindo as orientações dos organismos internacionais (GRUPO BANCO MUNDIAL, 1996). O Curso Superior de Tecnologia (CST) foi regulado e tem se desenvolvido a partir de então de modo bastante expressivo, seja pela ampliação dos cursos, das vagas, das modalidades de ensino, seja pelas possibilidades de financiamento e fomento público. Essa constatação nos conduz à reflexão acerca dos fundamentos ideológicos que direcionam a regulamentação e o desenvolvimento desses cursos.

Portanto, neste trabalho, tomamos como objetivo analisar as relações entre o gerencialismo e a regulação e desenvolvimento desse nível educacional. Para isso, nosso percurso analítico parte da concepção de gerencialismo como elemento

\footnotetext{
1 O conceito de "bloco no poder", segundo Poulantzas (2007) diz respeito à organização do Estado capitalista em classes e frações de classes que, em um contexto plural e "democrático", se expressa na reunião de representantes dessas frações de classes no âmbito do Estado e da classe dominante para produção de hegemonia.

2 Estado de bem-estar social.

${ }^{3}$ Partimos da concepção de Estado em seu sentido ampliado, que é resultado das relações entre sociedade política e sociedade civil, de acordo com a teoria gramsciana (GRAMSCI, 1989).
} 
superestrutural que fundamenta as relações de produção e reprodução da vida material no contexto de recomposição burguesa. Em segundo momento, apresentamos aspectos regulatórios e análise dos dados que demonstram 0 desenvolvimento dos CSTs no Brasil. Enfim, analisamos as relações entre os fundamentos superestruturais e os resultados apresentados.

Para isso, realizamos uma pesquisa básica, com abordagem qualitativa e finalidade explicativa, que tomou como procedimentos técnicos a pesquisa bibliográfica e documental, cujos instrumentos utilizados foram a análise de fontes bibliográficas e a documentação (GIL, 2008; LAKATOS; MARCONI, 1992; 2003; PRODANOV; FREITAS, 2013; SEVERINO, 2007).

\section{GERENCIALISMO E CONHECIMENTO NA SOCIEDADE CONTEMPORÂNEA}

Nosso ponto de partida é a compreensão da unidade indissolúvel entre teoria e prática, entre estrutura e superestrutura, entre objetividade e subjetividade, entre forças produtivas e relações de produção, entre o material e filosófico (MARX;

ENGELS, 2001; SANCHEZ-VÁZQUEZ, 1968; GRAMSCI, 2017). Portanto, entendemos que a materialização da totalidade concreta é resultado das relações de força, do movimento dialético no interior das relações de produção determinadas pelas forças produtivas. Assim, "as forças produtivas determinam as relações de produção que, por seu lado, condicionam as formas ideológicas e o Estado" (SANCHEZVÁZQUEZ, 1968, p. 166). Essas formas ideológicas compõem o conjunto superestrutural que expressa a realidade material e, ao mesmo tempo, é elemento condutor da hegemonia em torno de um determinado modo de produção (GRAMSCI, 2017).

O processo de recomposição burguesa é fundamentado e fundamenta um conjunto superestrutural necessário à manutenção da direção social pelo bloco no poder e à implementação do projeto de sociedade de novo tipo formulado como resposta à crise. Essa filosofia dominante é pedagogicamente massificada no conjunto social a fim de que a hegemonia se estabeleça e os sujeitos sociais a materializem em suas relações de modo espontâneo. Neste conjunto superestrutural, o gerencialismo ocupa certa centralidade no que concerne à função finalística do humano de novo tipo projetado nesse processo.

O amplo desenvolvimento da racionalização da produção iniciado a partir da difusão da administração científica, no início do século XX, culminou com a chamada revolução gerencial, que se mostrou mais consolidada a partir da segunda metade do mesmo século, a ponto de desenvolver a ideia de capitalismo gerencial (DUMÉNIL; LÉVY, 2013; BURNHAM, 1972). Do regime de acumulação rígida taylorista-fordista ao regime de acumulação flexível (toyotista), a sofisticação impulsionada pelo desenvolvimento científico e tecnológico se expressa para além do âmbito da produção e dita modelos para as relações humanas em sociedade.

Nesse contexto, "as relações entre capital e trabalho, bem como entre capital e natureza, são mediadas pela escolha de tecnologias e formas organizacionais" (HARVEY, 2011, p. 78). Tal processo, ao produzir saltos de qualidade, muitas vezes "levam os capitalistas a fetichizar a inovação tecnológica e organizacional como resposta para todas as orações" (HARVEY, 2011, p. 80). 
O conceito de gestão apresentado como "um conjunto de técnicas, destinadas a racionalizar e otimizar o funcionamento das organizações" (GAULEJAC, 2007, p. 35), bem como, o termo gerenciamento [no francês, management], trazem consigo a ideia de arranjar, instalar e providenciar. Assim, a ação de gerenciar consiste na organização de um sistema de poder, portanto, mesmo com aparência de objetividade, operacionalidade e pragmaticidade, "a gestão gerencialista é uma ideologia que traduz as atividades humanas em indicadores de desempenhos, e esses desempenhos em custos ou em benefícios" (GAULEJAC, 2007, p. 36).

Os paradigmas que fundamentam a gestão gerencialista são: a) objetivista, no qual a compreensão é oriunda da ação de medir, de calcular; b) funcionalista, no qual a organização é um dado, um sistema cuja finalidade é garantir a reprodução, para tanto, implica em regras, em ordens às quais os agentes devem se submeter; c) experimental, no qual a objetivação é um dado científico, onde o trabalhador é objeto de uma observação atenta a fim de formar atitudes que possibilitem o rendimento e a produtividade; d) utilitarista, no qual a reflexão está a serviço da ação a fim de maximizar a utilidade do recurso, por isso, aquilo que não for útil perde seu sentido; e) economista, o qual o humano é um fator/recurso da empresa, que transforma a sociedade em máquina de produção e o homem em agente a serviço da produção (GAULEJAC, 2007, p. 65-79).

Essa condução ideológica toma a premiação e a punição como instrumentos de conformação. Esses elementos são condizentes com a tese de que a hegemonia no capitalismo desenvolvido se expressa na mediação entre persuasão e coerção (GRAMSCI, 1989, p. 41). A lógica da premiação/punição expressa, ainda, a dupla perspectiva do gerencialismo pela combinação entre flexibilização e responsabilização (accountability). Para materialização dessa perspectiva de gestão, são desenvolvidas diversas formas de controle da produção, por instrumentos tecnológicos, a fim de promover a produtividade e racionalizar, no nível máximo possível, o processo produtivo, de modo a garantir a potencialização da lucratividade. A coerção presente na responsabilização é mascarada pela competição em busca da bonificação conquistada pelo alcance de metas da produção. Para efetividade disso, - regime de acumulação flexível requer um trabalhador de novo tipo, cujas competências sejam adaptáveis às demandas da produção. Portanto, no pacote da flexibilização, estão o empreendedorismo, a empregabilidade, a sustentabilidade que, em contextos de desemprego estrutural, conformam o trabalhador à intensificação da precariedade no trabalho.

Gerencialismo é a relação entre os conhecimentos da administração científica, agora denominada gestão, e a condução político-ideológica pautada nos valores sociais do capitalismo: produtividade, concorrência, lucratividade, empreendedorismo, pragmatismo, sustentabilidade etc., direcionados pela mediação entre flexibilidade e responsabilidade (LOCKE, 2009; KLIKAUER, 2013; QUIGGIN, 2003; CLARKE; NEWMAN, 1997; 2012; SOUZA, 2016). Gerencialismo é, portanto, uma condição superestrutural que serve para orientar as relações sociais na produção e reprodução da vida material, no estágio atual do capitalismo, a fim de racionalizar a produção, de modo que haja obtenção máxima de lucro e garanta o consentimento ativo do trabalhador em torno do novo padrão de vida e de sociedade. Portanto, essa concepção direciona tanto o desenvolvimento do regime de acumulação flexível, quanto a reforma do Estado. E mais ainda, essa lógica empresarial dita os padrões para todas as relações sociais, enfim, para própria vida humana a partir da perspectiva econômica, a fim de transformar tanto o humano, quanto suas relações sociais a partir 
da concepção instrumental do máximo utilitarismo, conforme esclarecem Dardot e Laval (2016, p. 27 e 31):

\begin{abstract}
Ela é a expressão mais clara de que estamos lidando não com uma "mercantilização sorrateira", mas com uma expansão da racionalidade de mercado a toda existência por meio da generalização da formaempresa. [...] Trata-se, na verdade, de produzir uma relação do sujeito individual com ele mesmo que seja homóloga à relação do capital com ele mesmo ou, mais precisamente, uma relação do sujeito com ele mesmo como "capital humano" que deve crescer indefinidamente, isto é, um valor que deve valorizar-se cada vez mais.
\end{abstract}

Nesse contexto, a ideia de conhecimento é central (DARDOT; LAVAL, 2016), bem como sua aplicação estratégica no bojo das políticas educacionais (DELORS, 1996). A estreita relação da concepção de conhecimento com o desenvolvimento econômico e social é demarcada na difusão do discurso de que estamos imersos numa "sociedade do conhecimento" (DRUCKER, 1993). Mas, conhecimento, nesse contexto, é "informação eficaz em ação, focalizada em resultados" (DRUCKER, 1993, p. 25). Essa concepção de conhecimento é utilitarista, tecnicista e pragmática - um conhecimento imediatamente interessado, que se confunde com informação. Portanto, seu valor é medido e hierarquizado a partir da produtividade que fundamenta, tornando-se instrumento e insumo para produção. Seu valor de uso e de troca está relacionado ao potencial econômico agregado tanto à sua utilização, quanto à sua mercantilização, que impulsiona sua fragmentação, cada mais radicalizada.

Para Hayek, que foi o primeiro a teorizá-lo, "knowledge" significa certo tipo de conhecimento diretamente utilizável no mercado, relacionado às circunstâncias de tempo e lugar - o conhecimento que se refere não ao porquê, mas ao quanto; o conhecimento que o indivíduo pode adquirir em sua prática, e cujo valor só ele pode avaliar; o conhecimento que ele pode utilizar de maneira proveitosa para vencer os outros na competição (DARDOT; LAVAL, 2016, p. 145).

O conhecimento imediatamente interessado, por ser uma mercadoria, assume as características de um mercado flexível e volátil, subsumido pela ideologia gerencial. Sua obsolescência está relacionada aos avanços científicos e tecnológicos cada vez mais velozes, que retroalimentam sua mercantilização. Nesse contexto, os mercados voltados à educação formal são aquecidos pela ideia de empregabilidade que fomenta a certificação em massa. Por outro lado, essa concepção economicista do conhecimento fundamenta a Teoria do Capital Humano (SHULTZ, 1973), que atesta o aumento da lucratividade a partir do investimento em educação.

A partir disso, observamos que os elementos: conhecimento interessado capital humano - empregabilidade/desemprego estrutural - mercantilização do conhecimento - obsolescência do conhecimento - conhecimento interessado formam um círculo vicioso e determinante, sobretudo no que diz respeito ao processo formal de educação, que expressa, de modo cada vez mais sofisticado a divisão social do conhecimento (BRANDÃO, 2006). A tendência desse processo é de intensificação da 
precariedade diante da certificação esvaziada de conhecimento e da desvalorização profissional da docência.

Figura 1: Ciclo da mercantilização do conhecimento interessado

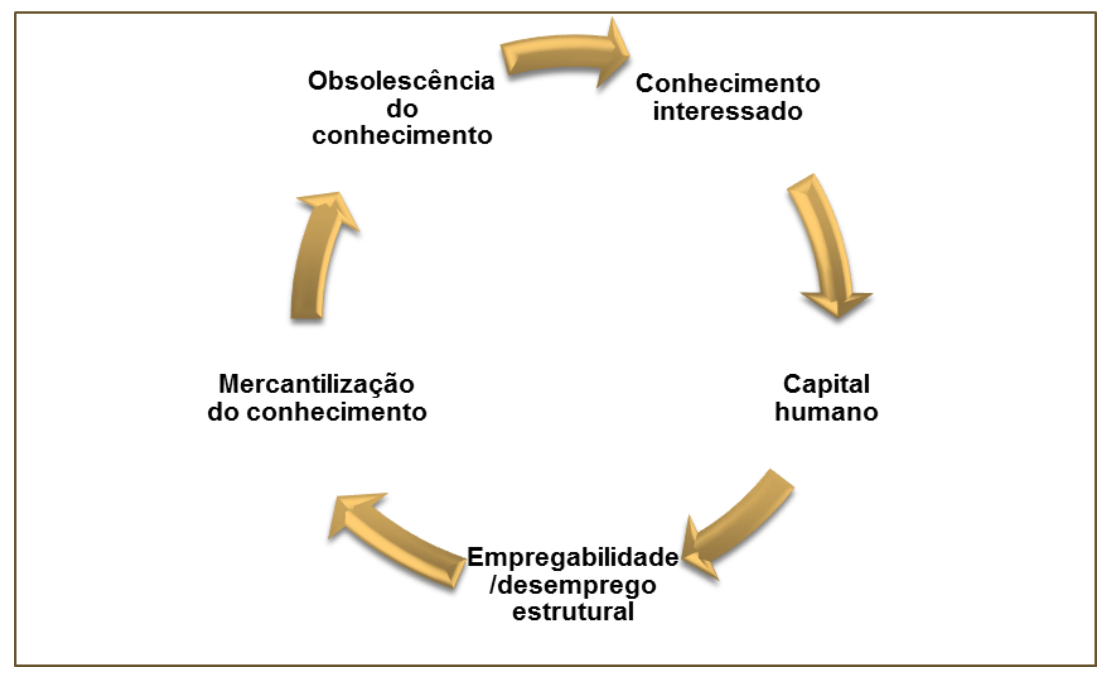

Fonte: Elaboração dos autores

Nesse contexto de franca expansão do gerencialismo que se materializa, dentre outros, na sofisticação e radicalização da divisão social do conhecimento, transformando a própria concepção de conhecimento, é que são regulados os CSTs, sobre o que tratamos a seguir.

\section{REGULAÇÃO E DESENVOLVIMENTO DO CURSO SUPERIOR DE TECNOLOGGIA}

Os CSTs estão previstos no Capítulo III - Da Educação Profissional: da educação profissional e tecnológica, da Lei de Diretrizes e Bases da Educação Nacional (LDBEN) (BRASIL, 1996) e no Decreto no 5.154/2004 (BRASIL, 2004), que foi alterado pelo Decreto № 8.268/2014 (BRASIL, 2014) e pela Lei oㅡ 11.741/2008 (BRASIL, 2008). Tais cursos são reconhecidos como nível superior, dispondo de todas as prerrogativas desse nível de formação - inclusive a possibilidade de acesso à pósgraduação - embora tenham carga horária reduzida: 1600 a 2400 horas, de acordo com o Parecer CNE/CES no 436/2001 (BRASIL, 2001) e com o Catálogo Nacional de Cursos Superiores de Tecnologia (BRASIL, 2016).

A Resolução CNE/CP no 3/20024 (BRASIL, 2002), que define as Diretrizes Curriculares Nacionais Gerais para a Educação Profissional de Nível Tecnológico, deixa clara a natureza imediatamente interessada dos cursos superiores de tecnologia ao estabelecer seus princípios: a) Incentivar o desenvolvimento da capacidade empreendedora e da compreensão do processo tecnológico, em suas causas e efeitos; b) Incentivar a produção e a inovação científico-tecnológica, e suas

\footnotetext{
${ }^{4}$ A partir de 05 de janeiro de 2021, entrou em vigor a Resolução CNE/CP no 1/2021 (BRASIL, 2021) substituindo essa Resolução, contudo, este artigo foi escrito antes da publicação das novas diretrizes.
} 
respectivas aplicações no mundo do trabalho; c) Desenvolver competências profissionais tecnológicas, gerais e específicas, para a gestão de processos e a produção de bens e serviços; d) Propiciar a compreensão e a avaliação dos impactos sociais, econômicos e ambientais resultantes da produção, gestão e incorporação de novas tecnologias; e) Promover a capacidade de continuar aprendendo e de acompanhar as mudanças nas condições do trabalho, bem como propiciar o prosseguimento de estudos em cursos de pós-graduação; f) Adotar a flexibilidade, a interdisciplinaridade, a contextualização e a atualização permanente dos cursos e seus currículos; e, g) Garantir a identidade do Perfil Profissional de conclusão do curso e da respectiva organização curricular (BRASIL, 2002).

Os sete princípios contidos no documento estão orientados pela lógica do gerencialismo. Desse modo, os cursos superiores de tecnologia estão voltados ao desenvolvimento da capacidade empreendedora para gestão e produção de bens e serviços. Os conhecimentos técnicos e tecnológicos se destinam à aplicação no mundo do trabalho, nos níveis subalternos de acordo com a hierarquia estabelecida no âmbito da divisão social do trabalho. O perfil do concluinte é de um humano flexível, apto à interdisciplinaridade e atualização permanente pelo desenvolvimento da capacidade de continuar aprendendo (BRASIL, 2002) - princípio norteado pela ideia de educação permanente e educação ao longo da vida capitaneado pelos organismos internacionais (DELORS, 1996).

Desde sua regulação, os CSTs estão em franca expansão. A ampliação da oferta desse nível educacional está expressa na criação de novas nomenclaturas de cursos e no aumento do número de vagas. De 2006 a 2016, o número absoluto de nomenclaturas desses cursos aumentou de 98 para 134, o que representa um acréscimo de 37\% (BRASIL, 2016).

De acordo com os dados do Censo da Educação Superior (INEP, 2019), no ano de 2018, havia no país 2.537 Instituições de Ensino Superior (IES), sendo 299 IES públicas e 2.228 privadas. Dentre essas, 1.352 IES ofertaram CSTs - o que corresponde a mais de $50 \%$ das IES existentes no Brasil. Essas IES ofertaram, nesse mesmo ano, 7.810 CSTs, dos quais mais de $80 \%$ ocorreram na rede privada e mais de $40 \%$ em IES cujo tipo de organização acadêmica é faculdade.

Gráfico 1: Série histórica do número de CST, por categoria administrativa - 2002 a 2018

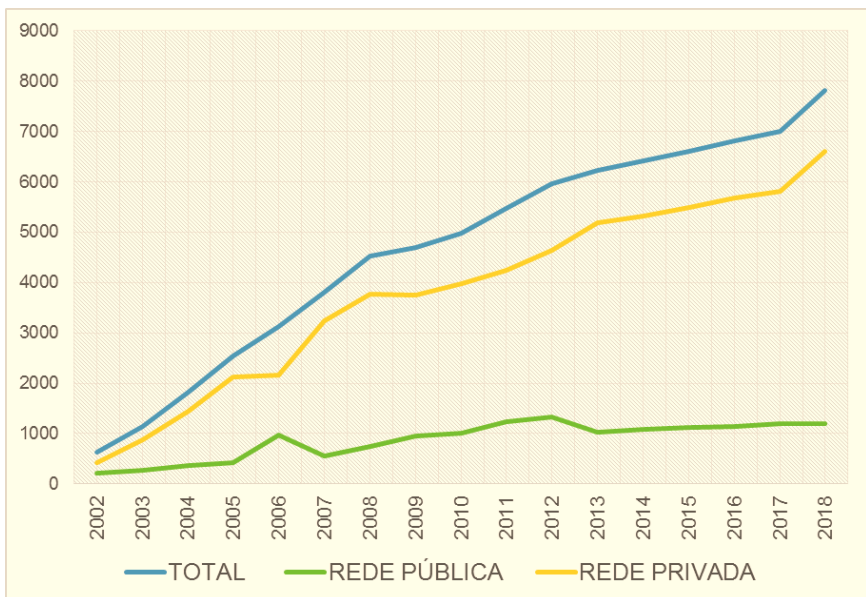

Fonte: INEP (2019), elaboração dos autores 
Do ano de 2010 para o ano de 2018, o número de alunos ingressos nesses cursos subiu de 362.204 para 719.569 , totalizando um aumento de $88 \%$ no período (INEP, 2019). Contudo, o número de ingressos apresenta diferenças por rede e modalidade. $\mathrm{O}$ aumento de ingressos na modalidade Educação à Distância (EaD) entre 2010 e 2018 foi superior a 290\%, enquanto, no mesmo período, o número de ingressos na modalidade presencial, na rede privada, apresentou queda de quase $5 \%$. Conforme demonstrado no Gráfico 2, a seguir, o número de ingressos nos CSTs na modalidade EaD ultrapassou o número de ingressos nesses cursos na modalidade presencial. Tendência que consolida a $\mathrm{EaD}$ como instrumento para certificação no nível superior por meio dos CSTs.

GRÁFICO 2: Série histórica do número de ingressos no CST, por modalidade de ensino - 2010 a 2018

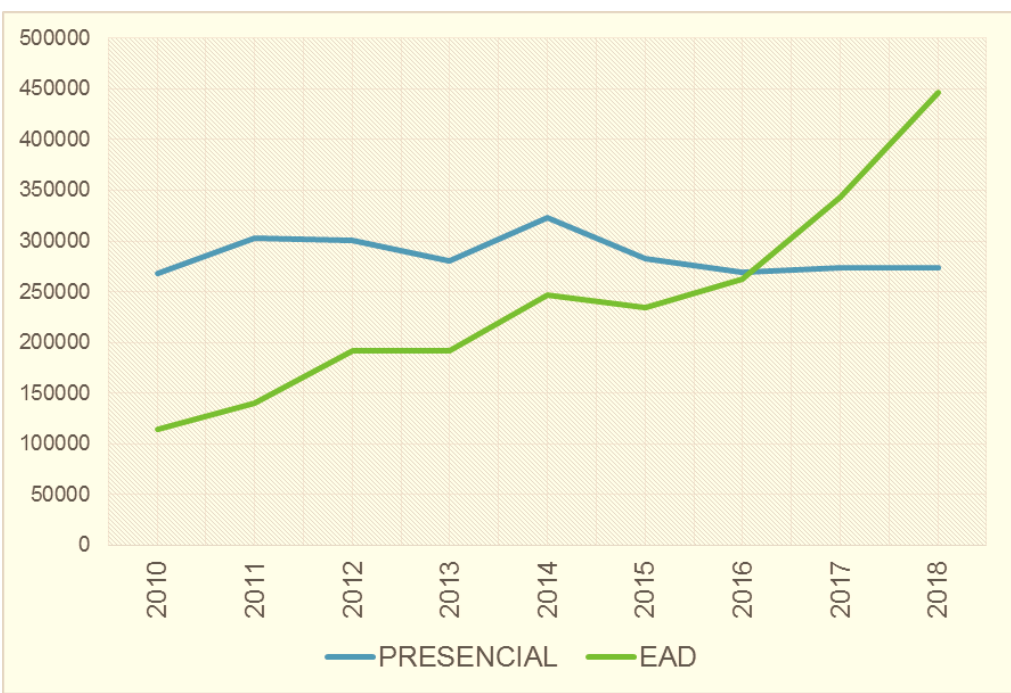

Fonte: INEP (2019), elaboração dos autores

A despeito do crescente número de ingressos nos CSTs na modalidade (EaD), essa modalidade representa cerca de $12 \%$ dos cursos ofertados, concentrados, principalmente, na rede privada de educação, tendo em vista que essa modalidade é quase inexpressiva na rede pública para esse tipo de curso superior. Por outro lado, quando comparados aos demais graus acadêmicos, o percentual de oferta na modalidade EaD dos CSTs apresenta quantitativo superior aos graus de bacharel e de licenciatura, nos quais representa $2 \%$ e 10\%, respectivamente.

A média de concluintes para os CSTs, no período de 2009 a 2017, totaliza cerca de $38 \%$ dos ingressos, sendo a modalidade EaD da rede privada a que representa a menor de média de conclusão (30\%). Nesse período, o número de inscritos nos CSTs foi de 4.478 .679 de discentes e o número de concluintes, de 1.705.235 (INEP, 2019).

Segundo dados do Censo do Ensino Superior, no período de 2009 a 2018, houve oferta de 20.894.257 vagas e 19.840.213 inscritos para os CSTs (INEP, 2019). Embora a diferença entre o somatório total da oferta de vagas pouco menor que 0 número total de inscritos, as diferenças são notáveis quando consideradas, de modo 
separado, as redes públicas e privadas e as modalidades presencial e EaD. A oferta de vagas na rede privada tem sido, constantemente superior ao total de inscritos, sobretudo na modalidade $\mathrm{EaD}$, onde o número de vagas é o dobro do número de inscritos.

Ocorre o oposto na rede pública, principalmente, na modalidade presencial, onde o número de inscritos se mostra cerca de 10 vezes superior ao número de vagas ofertadas. Fato que evidencia a demanda pela educação pública. Nesse caso, a demanda por vagas tem sido suprida pela rede privada que é beneficiada pelas políticas públicas de financiamento de bolsas de estudos.

Nos anos de 2014 e 2015, foram empregados mais de $\mathrm{R} \$ 17$ bilhões em recursos públicos para financiamento de formação na área de Educação Profissional Tecnológica, por meio do Programa Orçamentário "2031 - Educação Profissional e Tecnológica". Esse Programa Orçamentário teve como maiores favorecidos o Sistema $\mathrm{S}^{5}$, o Banco do Brasil, a Anhanguera Educacional, a Sociedade de Ensino Superior Estácio de Sá, a Ser Educacional, dentre outros. A partir de 2016, o Programa Orçamentário "2080 - Educação de Qualidade Para Todos" passou a centralizar a distribuição dos recursos, que totalizam cerca de $R \$ 45$ bilhões por ano (PORTAL DA TRANSPARÉNCIA, 2018). Tendo o Banco do Brasil como maior favorecido, por ter captado cerca de 1/3 desse recurso, nos anos de 2016 a 2018, e a Caixa Econômica Federal, o segundo maior favorecido, com a captação de $R \$ 300$ a $R \$ 400$ milhões por ano. São esses bancos os signatários dos contratos entre estudantes e governo nos programas PROUNI e FIES.

A despeito disso, instituições privadas de ensino superior estão constantemente presentes na lista dos maiores favorecidos do Programa orçamentário, embora alternem suas posições no ranking, principalmente a Fundação CESGRANRIO e Fundação Getúlio Vargas. Diante disso, tanto o aumento de cursos, quanto de inscritos e o emprego de recursos públicos na Educação Profissional Tecnológica demonstram o fomento governamental aos cursos superiores de tecnologia e o resultado alcançado pela política nos últimos anos.

Além dos dados apresentados até aqui, verificamos ainda que, a oferta de CSTs e o número de matrículas expressam as tendências desse tipo de curso. Entre 2010 e 2018, mais de 8 milhões de matrículas foram efetivadas nos CST, sendo que mais de $80 \%$ dessas matrículas foram concentradas em 25 cursos. O curso mais acessado durante o período foi o CST de Gestão de Recursos Humanos, com pouco menos de 1,4 milhões de matrículas; seguido pelo CST de Logística, com cerca de 700 mil matrículas. Aliás, os cursos nomeados com a palavra "Gestão" de alguma área específica representam $1 / 3$ desse grupo dos CSTs com maior número de matrículas, sem contar com os CSTs de Logística e Processos Gerenciais que também tratam, essencialmente, de gestão. Mais da metade do número total de matrícula nos CST entre 2010 e 2018 corresponde aos cursos que tratam, essencialmente, de gestão.

\footnotetext{
${ }^{5} \mathrm{O}$ Sistema S é um conjunto de organizações corporativas que oferecem treinamento profissional, assistência social, consultoria, pesquisa e assistência técnica. Esse Sistema é composto pelo Serviço Nacional de Aprendizagem Industrial (SENAI), Serviço Social do Comércio (SESC), Serviço Social da Indústria (SESI) e Serviço Nacional de Aprendizagem do Comércio (SENAC). Ainda existem o Serviço Nacional de Aprendizagem Rural (SENAR), o Serviço Nacional de Aprendizagem do Cooperativismo (SESCOOP) e o Serviço Social de Transporte (SEST).
} 
A metade dos CSTs ofertados em 2018 estão concentrados na área de "Ciências Sociais, Negócios e Direitos", especificamente em "Comércio e Administração". Esses cursos recebem, principalmente, nomenclaturas que relacionam a gestão em alguma área. Em seguida, os cursos com maior quantidade de oferta estão concentrados na área de "Ciências, Matemática e Computação", especificamente, computação. Em terceiro lugar, estão as ofertas de cursos na área de concentração "Serviços", especificamente, "Serviços pessoais". As três áreas juntas representam mais de $70 \%$ da oferta de CST, dentre os quais, o CST de Gestão de Recursos Humanos se destaca também como o mais ofertado pelas IES do país (INEP, 2019).

Tais constatações evidenciam o caráter mercantil do CST e sua destinação às camadas da classe trabalhadora ávidas por certificação, em busca de consolidação da empregabilidade, conforme desenvolvemos no tópico seguinte.

\section{A IMPOSIÇÃO DE UM MODELO EDUCATIVO PARA UMA SOCIEDADE DE NOVO TIPO}

O ponto essencial que fundamenta a regulação do CST é exatamente o que o difere dos demais graus educacionais: a carga horária enxuta. A racionalização dos recursos da produção em busca do aumento da lucratividade, que é fundamentada no gerencialismo, está presente na ideia de produção enxuta expressa na carga horária dos CSTs. Com a redução de carga horária são reduzidos os custos operacionais de funcionamento desse grau educacional, impactando diretamente nos valores de mensalidades, no caso da rede privada. O custo reduzido põe o CST em vantagem na concorrência com os demais graus educacionais. Por outro lado, no que diz respeito ao financiamento público, denota a concepção de redução dos gastos com políticas sociais, que também surge como projeto gerencialista no âmbito da reforma do Estado.

A redução da carga horária também traduz a concepção de parcelamento do conhecimento. Com enfoque estrito no aspecto pragmático, esse tipo de fragmentação denota a ideologia utilitarista que sustenta o grau de ensino e evidencia a sofisticação da divisão social do conhecimento, até então marcada, principalmente, pela tensão entre acesso ou não ao ensino superior. Assim, a dualidade educacional que se materializava, principalmente, na disposição dos níveis fundamentais de educação para a classe trabalhadora e nos níveis superiores destinados às classes dominantes, com a regulação dos CSTs, é expressa no nível superior, à medida que tais cursos são destinados às frações da classe trabalhadora não conformadas com o ensino médio técnico.

Essa concepção de conhecimento, em um contexto de amplo e contínuo desenvolvimento tecnológico, garante a obsolescência programada dos cursos, impondo a concepção de educação permanente e educação ao longo da vida, desenvolvida no bojo do projeto burguês em contextos de recomposição. Tal característica fomenta a mercantilização da educação e fortalece a transferência dos recursos públicos para o setor privado, que é responsável por mais de $80 \%$ desses cursos. Isso é evidenciado pelo fato de que as IES privadas, o Banco do Brasil e a Caixa Econômica figuram entre as instituições que mais recebem recursos públicos destinados à Educação Profissional e Tecnológica no Brasil. 
Além disso, o acesso à certificação em nível superior acirra as disputas pelos postos de emprego no mercado formal, fortalecendo a ideia de empregabilidade que fetichiza ainda mais a certificação, aquecendo o mercado educacional. Nesse sentido, a centralidade da ideia de conhecimento como mercadoria fomentada pelo gerencialismo fundamenta a regulação e o desenvolvimento dos CSTs.

Por outro lado, as Diretrizes Curriculares Nacionais Gerais para a Educação Profissional de Nível Tecnológico (BRASIL, 2002) direcionam o ensino do empreendedorismo. Nesse caso, empreender é ter a competência de utilizar o conhecimento desenvolvido nessa modalidade de ensino superior para produtividade e lucratividade. É a expressão da concepção de Capital Humano no fato de o próprio humano se tornar capaz de investir em si como mercadoria para vender a si mesmo e aferir lucro. Segundo Dardot e Laval (2016), a concepção gerencial da vida no atual contexto de desenvolvimento do capitalismo é expressa na racionalização da vida a ponto de o humano se tornar empresa de si. Coincidentemente, os CSTs são voltados para formação em áreas que possibilitam a gestão e a prestação de serviços em atividades laborais autônomas e informais. A demanda do capital de formar um público específico na gestão de si é expressa nesses resultados.

Esse público específico, por sua vez, são as frações da classe trabalhadora encantadas pelo discurso de empregabilidade, de Capital Humano, da meritocracia etc., que fundamentam a mediação entre flexibilidade e responsabilidade, próprias do gerencialismo. A evidência desse elemento está presente no aumento expressivo do ingresso nos CSTs na modalidade EaD na rede privada nos últimos anos, a ponto de superar a modalidade presencial. A escolha por um curso à distância, em uma IES privada evidencia o perfil de seu público oriundo das frações da classe trabalhadora: pessoas que não dispõem de tempo livre para formação, que pela formação precária não têm condições de disputar as vagas nas IES públicas e que têm urgência da certificação. Portanto, o CST é uma forma de atender à demanda da classe trabalhadora por certificação, até porque essa demanda serve aos interesses do capitalismo no seu atual estágio.

O desenvolvimento do grau de ensino se expressa a partir das características mencionadas, a saber: a) carga horária reduzida; b) conhecimento pragmático, utilitarista e fragmentado; c) currículo voltado à formação de empreendedorismo; d) cursos voltados à prestação de serviços que podemos classificar como trabalho simples. Essas características são somadas à realidade em que tais cursos se desenvolvem: a) predominância de ingressos no ensino à distância; b) predominância do ensino presencial em organizações acadêmicas do tipo faculdades; c) predominância de ingressos no ensino da rede privada; d) expressiva transferência de recursos públicos da Educação Profissional e Tecnológica para o setor privado (VEIGA, 2020).

A relação entre os fatores mencionados no parágrafo anterior demonstra a organização de um novo tipo de ensino superior, específico para classe trabalhadora, que distancia as possibilidades de seu acesso gratuito ao conhecimento e à pesquisa/ensino/extensão, próprias das IES públicas de tipo universidade. Desse modo, confere uma certificação que não representa possibilidades reais de disputar as vagas no mercado de emprego formal, tendo em vista que confere acesso ao nível superior, sem conferir acesso ao ensino superior em si. E ainda mais, pois, embora a legislação confira aos CSTs as prerrogativas dos demais graus, a possibilidade de ingresso na pós-graduação stricto senso é uma realidade distante, dada a ausência 
de componentes curriculares fundamentais à produção de conhecimento por meio de pesquisa científica.

A proposição desse novo modelo de ensino superior demanda uma nova concepção gerencial de IES que as faculdades e centros universitários atendem. Portanto, o fomento ao CST é uma maneira de promover a dissociabilidade entre ensino, pesquisa e extensão, que interfere diretamente na concepção de universidade que é referência na produção de conhecimento no Brasil. Assim sendo, o CST carrega em si o modelo gerencial de formação em nível superior para a classe trabalhadora.

Esse modelo de formação, em contextos de desemprego estrutural, serve à conformação para o subemprego e para o desemprego. Tal conformação se expressa na formação de "gestores" que sejam capazes de cumprir seu papel social e assumir o risco de empreender (VEIGA, 2020; VEIGA; FIGUEIREDO, 2020). Os cursos destinados à formação em prestação de serviços, os mais diversos, infundem possibilidades de empreendimentos que não requeiram investimentos financeiros de alta monta: como serviços de beleza e estética, de agricultura, de mecânica, de podologia, fotografia, dança, horticultura, alimentos etc. Nesse sentido, a concepção gerencialista de um trabalhador de novo tipo flexível, conformado às mais diversas realidades, está evidente nesse tipo de formação.

\section{CONCLUSÕES}

A condição superestrutural que delineia o regime de acumulação flexível e a reforma do Estado toma o gerencialismo como um de seus fundamentos. Nesse projeto de reestruturação da produção e reprodução da vida material, o objetivo de formar um novo modelo de homem e de sociedade impacta na proposição de diversas políticas condizentes com esse projeto.

Nesse contexto, a proposição de uma concepção de conhecimento nos moldes gerenciais e a própria prerrogativa de formar um humano flexível, adaptado e conformado a esse modelo de produção e reprodução da vida material impacta, dentre outras medidas, na regulação de um modelo de ensino superior totalmente orientado pelo gerencialismo, que evidencia o estágio atual da divisão social do conhecimento na sociedade de classes.

O CST toma como fundamento a visão de mundo, de humano e de sociedade próprias do gerencialismo. Nesse sentido, cumpre o papel estratégico de certificação de fração da classe trabalhadora, ao mesmo tempo em que lhe impõe a concepção de máximo utilitarismo à condição humana.

Esse projeto de formação é destinado à fração da classe trabalhadora não conformada com o ensino médio técnico e ávida por certificação. Portanto, o CST atende a essa demanda de certificação e, ainda mais, conforma para intensificação da precariedade do mercado de trabalho formal, para o subemprego e para o desemprego. Impondo a exigência da classe dirigente de que tais sujeitos desenvolvam a competência de gerir a si mesmos como recurso, sem alimentar a expectativa de direitos sociais. 


\section{REFERÊNCIAS}

BRANDÃO, Carlos Rodrigues. O que é educação popular. São Paulo: Brasiliense, 2006.

BRASIL. Lei no 9.394, de 20 de dezembro de 1996. Estabelece as diretrizes e bases da educação nacional. Brasília, DF, 1996.

BRASIL. Parecer CNE/CES no 436, de 06 de abril de 2001. Cursos Superiores de Tecnologia - Formação de Tecnólogos. Brasília, DF, 2001.

BRASIL. Resolução CNE/CP no 3, de 18 de dezembro de 2002. Institui as Diretrizes Curriculares Nacionais Gerais para a organização e o funcionamento dos cursos superiores de tecnologia. Brasília, DF, 2002.

BRASIL. Decreto no 5.154, de 23 de julho de 2004. Regulamenta o $\S 2^{\circ}$ do art. 36 e os arts. 39 a 41 da Lei no 9.394, de 20 de dezembro de 1996, que estabelece as diretrizes e bases da educação nacional, e dá outras providências. Brasília, DF, 2004.

BRASIL. Lei no 11.741, de 16 de julho de 2008. Altera dispositivos da Lei no 9.394, de 20 de dezembro de 1996, que estabelece as diretrizes e bases da educação nacional, para redimensionar, institucionalizar e integrar as ações da educação profissional técnica de nível médio, da educação de jovens e adultos e da educação profissional e tecnológica. Brasília, DF, 2008.

BRASIL. Decreto no 8.268, de 18 de julho de 2014. Altera o Decreto no 5.154, de 23 de julho de 2004, que regulamenta o $\S 2^{\circ}$ do art. 36 e os arts. 39 a 41 da Lei no 9.394, de 20 de dezembro de 1996. Brasília, DF, 2014.

BRASIL. MEC (2016). Catálogo nacional dos cursos superiores de tecnologia. Brasília, DF, 2016.

BRASIL. Decreto no 9.235, de 15 de dezembro de 2017. Dispõe sobre o exercício das funções de regulação, supervisão e avaliação das instituições de educação superior e dos cursos superiores de graduação e de pós-graduação no sistema federal de ensino. Brasília, DF, 2017.

BRASIL. Resolução CNE/CP no 1, de 05 de janeiro de 2021. Define as Diretrizes Curriculares Nacionais Gerais para a Educação Profissional e Tecnológica. Brasília, DF, 2021.

BURNHAM, James. The managerial revolution: what is happening in the world. Santa Bárbara: Praeger, 1972.

CLARKE, John; NEWMAN, Janet. The managerial State. Londres: Ed. Sage Publications, 1997.

CLARKE, John; NEWMAN, Janet. Gerencialismo. Educação e Realidade, Porto Alegre, v. 37, n. 2, p. 353-381, maio/ago. 2012.

DARDOT, Pierre; LAVAL, Christian. A nova razão do mundo: ensaio sobre a sociedade neoliberal. São Paulo: Boitempo, 2016.

DELORS, Jacques. Educação, um tesouro a descobrir: relatório para a UNESCO da Comissão Internacional sobre Educação para o século XXI. São Paulo: UNESCO/Cortez, 1996. 
DRUCKER, Peter. A sociedade pós-capitalista. São Paulo: Pioneira, 1993.

DUMÉNIL, Gérard; LÉVY, Dominique. A crise do neoliberalismo. São Paulo: Boitempo, 2013.

GIL, Antônio Carlos. Métodos e técnicas de pesquisa social. São Paulo: Atlas, 2008.

GAULEJAC, Vincent de. Gestão como doença social: ideologia, poder gerencialista e fragmentação social. São Paulo: Ideia das Letras, 2007.

GRAMSCI, Antonio. Cadernos do cárcere. Rio de Janeiro: Civilização Brasileira, 2017. Vol. 1.

GRAMSCI, Antonio. Maquiavel, a política e o Estado moderno. Rio de Janeiro: Civilização Brasileira, 1989.

GRAMSCI, Antonio. Cadernos do cárcere. Rio de Janeiro: Civilização Brasileira, 2016. Vol. 3.

GRUPO BANCO MUNDIAL. Prioridades y estrategias para la educacion: examen del Banco Mundial. Washington (DC), 1996.

HARVEY, David. Breve historia del neoliberalismo. Madri: Akal, 2007.

HARVEY, David. O enigma do capital e as crises do capitalismo. São Paulo: Boitempo, 2011.

HOBSBAWM, Eric. A era do capital: 1848-1875. São Paulo: Paz e Terra, 1977.

INEP. Inepdata: Censo da educação superior, microdados de 2018. Brasília, DF: 2019. Disponível em: http://portal.inep.gov.br/web/guest/microdados. Acesso em: 05/06/2020.

LOCKE, Robert R. Managerialism and the Demise of the Big Three. Real-World Economics Review, Bristol (UK), Issue n. 51, p. 28-47, 1 December 2009.

KLIKAUER, Thomas. Managerialism, a critique of an ideology. Reino Unido:

Palgrave Macmillan UK, 2013.

MARCONI, Marina de Andrade; LAKATOS, Eva Maria. Fundamentos de Metodologia Científica. São Paulo: Atlas, 2003.

MARCONI, Marina de Andrade; LAKATOS, Eva Maria. Metodologia do trabalho científico. São Paulo: Atlas, 1992.

MARX, Karl; ENGELS, Friedrich. A ideologia alemã. São Paulo: Martins Fontes, 2001.

PORTAL DA TRANSPARÊNCIA, 2019. Portal em Gráficos. Brasília (DF): 2018.

Disponível em:

http://www.portaldatransparencia.gov.br/graficos/transferenciasporfuncao/. Acesso em: 20/03/2020.

POULANTZAS, Nicos. Poder político y clases sociales en el estado capitalista. Cerro del Agua: Siglo Veintiuno Editores, 2007.

PRODANOV, Cleber Cristiano; FREITAS, Ernani Cesar de. Metodologia do trabalho científico: métodos e técnicas da pesquisa e do trabalho acadêmico. Novo Hamburgo: Universidade FEEVALE, 2013. 
QUIGGIN, John. Word for Wednesday: managerialism (definition). Commentary on Australian \& world events from a social-democratic perspective. SITE. 16/Jul/2003.

SANCHÉZ-VÁZQUEZ, Adolfo. Filosofia da práxis. Rio de Janeiro: Paz e terra, 1968.

SEVERINO, Antônio Joaquim. Metodologia do trabalho científico. São Paulo: Cortez, 2007.

SHULTZ, T. W. O capital humano: investimentos em educação e pesquisa. Rio de Janeiro: Ed. Zahar, 1973.

SOUZA, José dos Santos. Projeto Gerencialismo. Arquivo Mp4. UFRRJ, GTPS, 2016.

SOUZA, José dos Santos. Institutos federais de educação, ciência e tecnologia: a materialidade do conflito de classe na concepção e na política de formação humana. In: SOUSA, José Vieira; BOTELHO, Arlete de Freitas; GRIBOSKI, Cláudia Maffini (Org.). Organização institucional e acadêmica na expansão da Educação Superior. Anápolis: Editora Universidade Estadual de Goiás, 2018, p. 135-150.

VEIGA, Célia Cristina Pereira da Silva. Determinantes sócio-históricos das mudanças recentes na gestão da educação profissional tecnológica no Brasil. Nova Iguaçu (RJ); Seropédica (RJ): 2020. 377 p. Tese [Doutorado em educação] Programa de Pós-graduação em Educação, Contextos Contemporâneos e Demandas Populares (PPGEduc), Instituto de Educação/Instituto Multidisciplinar, Universidade Federal Rural do Rio de Janeiro (UFRRJ).

VEIGA, Célia Cristina Pereira da Silva; FIGUEIREDO, Bruno de Oliveira. A proposição de cursos superiores de tecnologia para formação do trabalhador de novo tipo. RTPS - Revista Trabalho, Política e Sociedade, Rio de Janeiro, v. 5, n. 8 , p. p. $139-157,25$ maio 2020. 